\title{
MAKING USE OF THE DIRECT ELECTROCHEMISTRY OF ENZYMES
}

\section{H. Allen O. Hil}

(Central Chemistry Laboratory, South Parks Rd, Oxford OXI 3QH)

\section{Abstract}

There are many examples in the literature, and a few in commerce, of the employment of the electrochemistry of redox enzymes for analytical purposes. Though attention to the direct electrochemistry of redox enzymes is growing, so far, there have been no commercial applications of redox enzymes. That might be about to change.

Keywords: Electrochemistry; redox proteins; redox enzymes; scanning probe microscopy; sensors.

\section{Introduction}

The use of enzymes as components of biosensors is now common even of those whose detection methods are based on one or other electrochemical method. Essentially all of such devices, in which the detection method is amperometric, rely on indirect electron transfer between electrode and enzyme. We have been concerned for over a decade to exploit instead direct electron transfer, i.e., avoiding the need for a mediator. Of course, there are other potential advantages in using direct methods, in particular, the possibility of developing devices that make use of two or more enzymes side-by-side without the danger of cross-talk between the electrodes. In this paper, I discuss the various factors that are pertinent to the execution and use of direct electron transfer.

\section{Discussion}

The enzyme: Essentially all electrochemical experiments are conducted in solution and, when one is concerned with the electrochemistry of biological materials, water is obviously the preferred solvent. Thus we must consider the solution structure of a protein. The structure of many proteins is available in the crystalline state but, over the past ten years or so, many structures of small proteins have been determined [1] by NMR spectroscopy. Both methods now emphasize that the structures of most proteins have significant portions, usually on the surface, that are in motion, i.e., both individual residues and sections of the peptide backbone are better considered as dynamic ensembles. There is some evidence that redox proteins, such as cytochrome $c$ or plastocyanin, are quite rigid but, even with these proteins, the surface is in motion. With enzymes, there is little doubt that, not only are the surface sections in motion but there is usually some movement that is an essential part of the catalytic process. This indicates that while, of course, the structure determined 
by diffraction methods is a useful, sometimes essential, guide to achieving the proper examination of the electrochemistry of proteins, knowledge of the mobility of the enzyme after it is adsorbed on the electrode surface or when mutations are made, would be desirable.

The electrode: Various materials have been employed as electrodes in bioelectrochemistry but only a very small number of relevant processes have employed single crystal faces of metallic systems as electrodes. Basal plane surfaces of pyrolytic graphite has been used, of course, but even with these, significant care is usually not taken to ensure the regularity of the surface at the atomic level. Edge plane graphite, though effective for many enzymes with or without facilitators (promoters), is a horrendously complex surface and it would be foolishly optimistic to expect that the arrangement of the enzyme is, currently, understood. In addition, the adsorption of, say, the buffer material or of adventitious adsorbates leads to and surface being ill-defined. Thus, many of the explanations [2] for the success of various configurations, for example, by the use of materials as facilitators or the employment of compounds that seek to adsorb proteins or enzymes on electrode surfaces, as in protein film voltammetry [3], thought they may be correct, have not really been established. Thus, when facilitators (then called promoters) were first employed [4] some twenty-five years ago, it was thought that they exerted their effects through keeping adventitious adsorbates off the surface of the electrode or ensuring that the surface of the electrode was sufficiently hydrophilic (and hence allowing the proteins to approach closely) or providing a surface to which the proteins could adsorb or ensuring that the protein adsorbed in the 'correct' orientation. The latter would seem to assume that the protein adsorbs in just one orientation but ignores the possibility that the protein can diffuse in two-dimensions across the surface such that, if there is a preferred pathway for electron transfer (though the latest work suggests [5] that it is simply a distance-dependent process), there is a chance that this correct orientation will be expressed. Electron transfer between electrode and enzyme is therefore most likely to be a function of the distance of the 'edge' of the enzyme from the surface and dependent on the topology of the enzyme. A thorough analysis [6] of the electrochemistry of cytochrome $c$ at a gold electrode modified with 4,4'-bipyridyl, the first facilitator (promoter) introduced, showed that the true firstorder electron transfer rate was fast, between $50-100 \mathrm{~s}^{-1}$

The use of edge-plane pyrolytic graphite proved [7] valuable, trivially because positivelycharged proteins such as cytochrome $c$ gave good electrochemistry but mainly because, in the presence of cations such as magnesium(II), negatively-charged proteins such as the copper protein, plastocyanin, behaved well. It mustn't be forgotten that most proteins are negatively-charged: for example, some two-iron ferredoxins carry a charge of -14 at $\mathrm{pH} 7$ ! Of course, the distribution of this charge, characterised at a macroscopic level by the dipole moment, may be important but this absolute charge seems to be crucial in the interaction between the protein and the electrode either by forming ion pairs with the negatively-charged residues of the protein and/or interacting with negatively-charged groups on the electrode. Of all these adjunct facilitators, the aminoglycosides introduced [8] by Armstrong are particularly effective and allowed the development of the technique of protein film voltammetry [3] which is extremely miserly in its use of the protein (since it is effectively irreversibly adsorbed on the electrode) and the interpretation of the data is not complicated by the effects of diffusion.

Electrochemistry of enzymes: Prior to the discovery of protein electrochemistry, much use had been made of mediators such as paraquat or ferricyanide. Redox proteins themselves can act as mediators and, before the electrochemistry of enzymes was achieved in the middle eighties, the catalytic power inherent through enzymes was exploited in, for example, the coupling of cytochrome $c$ to the enzyme, carbon monoxide oxidoreductase [9] or even to its natural host, the key [10] component of the mitochondrion, cytochrome $c$ oxidase. One feature of redox enzymes that was pointed out [2] in the eighties, is that some have an inherent route for electron transfer to the active site because they have a partner protein responsible for electron transfer to or from the enzyme, the so-called extrinsic redox enzymes, there are others, intrinsic redox enzymes, that are completely self-contained in that the two substrates, for example, glucose and dioxygen, attend separately or simultaneously, the active site of glucose oxidase: whether or not electron transfer can occur at an electrode depends on the distance of this site from the surface and hence from the electrode. If the site is close to the surface, then electrochemistry may ensue but it is not an inherent feature of the enzyme.

Though there had been a number of earlier reports of the direct electrochemistry of redox enzymes, it was not until the eighties $[8,11]$ that the subject was put on a firm footing. For example, it was found that the electrochemistry [11] of $p$-cresolmethylhydroxylase was well behaved; presumably the electron transfer occurred through the cytochrome portion of the enzyme. Most importantly, the enzyme retained its catalytic properties whilst the electrochemistry was being observed and this pointed the way towards both the detailed investigation and its possible use in sensors. Similar results were obtained with, for example, methylamine dehydrogenase [12]. Armstrong and his colleagues have made [3] excellent use of protein film voltammetry to investigate, not only the electrochemistry of redox proteins, particularly the ferredoxins but also redox enzymes such as fumarate reductase. We have been concerned to tackle challenging and difficult enzymes such as cytochrome P450 and methane monooxygenase. The former, which is also a monooxygenase, catalyses the oxidation of a wide range of substrates, introducing an oxygenated function in place of an alkyl or aryl hydrogen. Wong [13] has worked extensively on the genetic engineering of Pseudomonas putida cytochrome P450, finding many hybrids that oxidise hydrocarbons from propane to phenanthrene. Using electrochemical methods it has been 
possible $[14,15]$ to arrange electron transfer to both $\mathrm{P} 450$ and the complex formed between P450 and its partner protein, putidaredoxin: the remaining problem in achieving electrocatalysis is the proper delivery of dioxygen at a rate compatible with the electrochemical reaction and not simply forming hydrogen peroxide. In retrospect, the use of electrochemistry in the study of the cytochrome $\mathrm{P} 450$ case turned out to be more difficult than that using methane monooxygenase.

The oxidation of methane is a notoriously challenging task for chemists yet the biology has solved this problem. There are two enzymes, a soluble system, which contains iron, and a particulate ensemble that uses copper at the active site. The former is a three-component system, the hydroxylase $\mathrm{A}$ and a reductase $\mathrm{C}$ linked by a small protein, $\mathrm{B}$. The reaction scheme shows that, like the P450 case, hydrogen peroxide can be formed if conversion of, say, methane to methanol does not take place. The electrochemistry of the enzyme was achieved [16] which is only to be expected since it is an extrinsic redox enzyme: more importantly, electrocatalysis occurred as shown by the conversion of methane to methanol.

The structures of electrode surfaces upon which are adsorbed enzymes: It may be much more difficult to understand the structure of enzymes on electrode surfaces for the reasons referred to earlier: not only is there the problem of local mobility but there can often be extensive rearrangement of the enzyme in response to the substrate and other factors and the relative ease of distortion may lead to the enzyme 'collapsing' on the electrode surface. As well, the mode of the adsorption of facilitators and enzymes depends on the potential applied to the electrode. For those electrochemistry has already been reported one can be confident that, perhaps due to presence of facilitators, their integrity is intact. The first attempt to use Scanning Probe Microscopy (SPM) to investigate electrode surfaces upon which are adsorbed enzymes has been [15] published. Obtaining the SPM of proteins or enzymes is that it is pointless unless the measurements are made in solution since the solvent is suspected of having a profound influence on the structures and activities of proteins and enzymes. Scanning Tunnelling Microscopy (STM) proved particular valuable yielding $[15,17,18]$ the images of individual proteins and enzymes. More information was obtained from some of the images than expected and attempts are being made to rationalise the appearance of seemingly sub-molecular details. For example, in the STM of the zinc-containing protein, metallothionein, not only was the topology of the images remarkably similar to that expected from the diffraction and NMR data, there appeared to be enhanced portions in appropriate positions for the seven zinc ions in each molecule. More relevant to electrochemistry, similar effects were observed in the STM of rubredoxin and especially in cytochrome P450 where it appeared that enhancements occurred at positions close to those expected for the heme group. In future, attempts will be made to gain images of cytochrome P450 in association with putidaredoxin and putidaredoxin reductase, the enzyme's natural partners. Ultimately it would be interesting to be able to place the enzymes on the surface in a defined manner leading to useful nanotechnological applications.

\section{Conclusions}

Now that a sufficiently large number of redox enzymes give rise to electrochemistry, what use can be made of them? Is it ever going to be possible to exploit them towards a useful end as was done [19] for the indirect electrochemistry of, e.g., glucose oxidase via ferrocene as the basis for a sensor for glucose, of great use to diabetics? One possibility we have considered is their exploitation in sensors that make [20] use of microelectrodes, arranged in arrays because the response to analytes should not be disturbed by latter diffusion of the mediator normally present. We wait, with interest, to see if there is a third generation of electrochemically-based biosensors.

\section{Acknowledgments}

I thank the members of my research group, particularly Dr. E. N. K. Wallace for help freely given and the EPSRC for financial assistance.

\section{References}

[1] I. D. Campbell and A. K Downing, Nature. Struct. Biol. 5(Suppl.), (1998), 496-499.

[2] F. A. Armstrong, H. A. O. Hill and N. J. Walton, Acc. Chem. Res. 21, (1988), 407-413.

[3] F. A. Armstrong, H. A. Heering, and J. Hirst, Chem. Soc. Rev. 26, (1997), 169-179.

[4] M. J. Eddowes and H. A. O. Hill, J. Chem. Soc. Chem. Commun. (1977), 771-772

[5] C. C. Page, C. C. Moser, X. Chen and P. L. Dutton, Nature 402 (1999), 47-52.

[6] W. J. Albery, M. J. Eddowes, H. A. O. Hill and A. R. Hillmann, J. Amer. Chem. Soc, 103 , (1981), 3904-3910.

[7] F. A. Armstrong, H. A. O. Hill, B. N. Oliver and N. J. Walton, J. Amer. Chem. Soc. 106, (1984), 921-923.

[8] F. A. Armstrong and A. M. Lannon, J. Am. Chem. Soc., 109, (1987), 7211-12.

[9] A. P. F. Turner, W. J. Aston, I. J. Higgins, J. M. Bell, J. Colby, G. Davis and H. A. O. Hill, Anal. Chim. Acta 163, (1984), 161-174

[10] H. A. O. Hill, N. J. Walton and I. J. Higgins, FEBS Lett. 126, (1981), 282-284.

[11] L. H. Guo, H. A. O. Hill, D. J. Hopper, G. A. Lawrence and G. S. Sanghera, J. Electroanal. Chem., 266, (1989), 379-390

[12] M. Ubbink, N. I. Hunt, H. A. O. Hill and G. W. Canters, Eu. J. Biochem., 222, (1994), 561- 
[13] C. F. Harford-Cross, A. B. Carmichael, F. K. Allan, P. A. England, D. A. Rouch and L-L. Wong, Protein Eng. 13 (2000), 121-128.

[14] J. Kazlauskaite, A. C. G. Westlake, L-L. Wong and H. A. O. Hill, J. Chem. Soc. Chem Comm., (1996), 2189-2190.

[15] J. J. Davis, D. Djuricic, K. K. W. Lo, E. M. K. Wallace, L-L. Wong and H. A. O. Hill, Faraday Discuss, 16, (2000), 15-22.

[16] J. Kazlauskaite, H. A. O. Hill, P. Wilkins and H. Dalton, Eur. J. Biochem. 241, (1996), 552 556; Y. Astier, S. Bulendra, H. Dalton and H. A. O. Hill, to be submitted.

[17] J. J. Davis, H. A. O. Hill, A. Kurz, C. Jacob, W. Maret and B. L. Vallee, PhysChemComm, 1, (1998), 20-26.

[18] R. Mukhopadhyay, J. J. Davis, P. Kyritsis, H. A. O. Hill and J. Meyer, J. Inorg. Biochem. 78, (2000), 251-254

[19] A. E. G. Cass, G. Davis, G. D. Francis, H. A. O. Hill, W. J. Aston, I. J. Higgins, E.V. Plotkin, L. D. L. Scott and A. P. F. Turner, Anal. Chem. 56, (1984), 667-671.

[20] M. Kudera, A. Aithen, Li Jiang, S. Kaneko, H. A. O. Hill, P. J. Dobson, P. A. Leigh and W. W. McIntire, J. Electroanal. Chem., 495, (2000), 36-4

\section{WHAT CAN ELECTROCHEMISTRY DO FOR THE ENVIRONMENT?}

J.González-García, V. García, J. Iniesta, V. Montiel, A. Aldaz*

Departamento de Quimica-Fisica. Universidad de Alicante. Apdo. 99. 03080 Alicante. España E-mail: aldaz@ua.es.

\section{Abstract.}

Electrochemistry offers many methods for decreasing the contamination produced by different industrial processes. Among these, Electrochemical Synthesis and Electrochemical Degradation of Organic Compounds in wastewater are two of the more promising ones. There is no doubt that the best way to avoid pollution is to eliminate the process that produces it and in this way very polluting chemical syntheses can be substituted by more cleaner electrochemical processes. As an example of this, the electrochemical synthesis of L-cysteine derivatives from L-cystine will be described. As far as the second method is concerned, the electrochemical degradation of wastewater containing organics appears to be very effective when the wastewater can not be biologically treated and when the oxidation is only carried out until the wastewater can be treated by biological methods. Details of the procedure followed for the development of a pre-industrial process will be shown for the treatment of industrial wastewater containing phenol.

Keywords:L-cysteine, L-cystine; electrochemical synthesis; electrochemical degradation; environmental electrochemistry.

Introducción.

La contaminación medioambiental es uno de los problemas más preocupantes de nuestro desarrollo actual y para evitarla cada día se endurece la legislación sobre vertidos industriales, sean estos sólidos, líquidos o gaseosos. A la Industria Química se le acusa de ser una de las fuentes más importantes de contaminación medioambiental y esto crea una mala imagen social que se extiende no solo a la Química sino también a las áreas con ella relacionadas, olvidando, en muchos casos, que existen multitud de métodos químicos para tratar efluentes industriales de cualquier origen y convertirlos en inocuos. 